\title{
Equívocos arraigados no meio pecuário sobre deficiências e suplementação minerais em bovinos no Brasil ${ }^{1}$
}

\author{
Pedro Malafaia ${ }^{2 *}$, Rogério Magnoli Costa ${ }^{3}$, Marilene F. Brito ${ }^{5}$, Paulo V. Peixoto ${ }^{2}$, \\ José Diomedes Barbosa ${ }^{4}$, Carlos Hubinger Tokarnia ${ }^{2}$ e Jürgen Döbereiner ${ }^{6}$
}

\begin{abstract}
Malafaia P., Costa R.M., Brito M.F., Peixoto P.V., Barbosa J.D., Tokarnia C.H. \& Döbereiner J. 2014. [Erroneous interpretations regarding mineral deficiencies and supplementation of cattle in Brazil.] Equívocos arraigados no meio pecuário sobre deficiências e suplementação minerais em bovinos no Brasil. Pesquisa Veterinária Brasileira 34(3):244-249. Departamento de Nutrição Animal e Pastagem, Instituto de Zootecnia, Universidade Federal Rural do Rio de Janeiro, BR 465 Km 7, Seropédica, RJ 23890-000, Brazil. E-mail: malafaia_ufrrj@yahoo.com.br

The economic importance of mineral deficiencies in cattle and their supplementation for animal health and production is well established. But in spite of the existing knowledge and conscience of professionals on this subject in Brazil, there are numerous erroneous interpretations and superstitions on mineral supplementation for cattle, together with indiscriminate commercialization of mineral mixtures; the latter, thoroughly accepted and applied in the rural area, causes considerable economic losses to the cattle industry. In this article of general interest we discuss, one by one, the most important misunderstandings and superstitions regarding this subject.
\end{abstract}

INDEX TERMS: Cattle, mineral deficiencies, mineral supplementation.

RESUMO.- Está bem estabelecida a importância que as deficiências e a suplementação minerais exercem na sanidade, produtividade e economicidade da atividade pecuária brasileira. Apesar de os conhecimentos sobre este assunto no meio acadêmico no Brasil serem sólidos, há numerosos equívocos e crendices sobre a suplementação mineral, aliados à comercialização indiscriminada de suplementos minerais, amplamente aceitos e aplicados no meio rural, o que causa consideráveis prejuízos ao setor pecuário. Neste artigo de interesse geral são discutidos, um por um, as

\footnotetext{
${ }^{1}$ Recebido em 31 de janeiro de 2014.

Aceito para publicação em 14 de fevereiro de 2014.

${ }^{2}$ Departamento de Nutrição Animal e Pastagem, Instituto de Zootecnia (IZ), Universidade Federal Rural do Rio de Janeiro (UFRRJ), Seropédica, RJ 23890000, Brasil. *Autor para correspondência: malafaia_ufrrj@yahoo.com.br

${ }^{3}$ Zootecnista, Êxito Rural Consultoria em Pecuária, Rua Professora Chiquita Fernandes 990, Araçatuba, SP 16025-100, Brasil. E-mail: rogerio@ exitorural.com.br

${ }^{4}$ Escola de Medicina Veterinária, Campus Castanhal da Universidade Federal do Pará (UFPA), Rua Maximino Porpino 1000, Castanhal, PA 68740080, Brasil. E-mail: diomedes@ufpa.br

${ }^{5}$ Departamento de Epidemiologia e Saúde Pública, Instituto de Veterinária (IV), UFRRJ, Seropédica, RJ 23890-000, Brasil.

${ }^{6}$ Projeto Sanidade Animal, Convênio Embrapa/UFRRJ, Seropédica, RJ 23851-970, Brasil.
}

mais importantes interpretações errôneas a respeito desse tema.

TERMOS DE INDEXAÇÃO: Bovinos, deficiências minerais, suplementação mineral.

\section{INTRODUÇÃO}

O saber, sempre fundamentado nas premissas do método científico, gerado no Brasil a respeito das deficiências e suplementação mineral em bovinos é muito vasto e sólido e, por isso, tem notória aceitação pela comunidade científica nacional e internacional. Contudo, por mais paradoxal que possa ser, ainda nos deparamos com inúmeros equívocos ou até mesmo crendices sobre esse assunto que, além de gerarem confusões, também são causa de consideráveis prejuízos econômicos ao setor pecuário. Todavia, é necessário diferenciar crença de dúvida, pois esses são dois estados mentais relativamente fáceis de distinguir. 0 estado de dúvida produz sensação incomodativa e insatisfatória no qual o ser humano reage, e tenta adquirir informações, para se tornar esclarecido; diferentemente, o estado de crença é calmo e satisfatório, daí sendo mais "fácil" permanecer na "crença" do que tentar romper com o "já estabelecido" e criar novas proposições ou novo pensamento crítico.

O fato incontestável de que os minerais são necessários em inúmeras funções estruturais e metabólicas nos seres 
vivos, criou a equivocada percepção de que esses nutrientes sempre devem ser suplementados aos animais. Porém, é preciso ter-se sempre em mente que os alimentos e a água já contêm minerais, em maior ou menor quantidade, e que a suplementação destes só deverá ser feita se os mesmos não suprirem as necessidades de um ou outro mineral. Em muitas situações, os alimentos de boa qualidade podem suprir grande parte ou até mesmo todas as necessidades em minerais dos animais (Malafaia et al. 2003, Peixoto et al. 2003, Malafaia et al. 2004).

Em função da notória importância que as deficiências e a suplementação mineral exercem na sanidade, produtividade e economicidade da atividade pecuária, algumas práticas, amplamente aceitas e aplicadas rotineiramente, sem questionamentos, precisam ser revistas; nós as denominamos de equívocos e crendices sobre suplementação mineral, descritos em seguida.

A presente revisão tem por objetivo descrever os principais equívocos e crendices que existem no meio pecuário brasileiro sobre as deficiências e a suplementação mineral dos bovinos e tem como base bibliográfica o livro Deficiências Minerais em Animais de Produção (Tokarnia et al. 2010) e os artigos Suplementação protéico-energética para bovinos criados em pastagens: Aspectos teóricos e principais resultados publicados no Brasil (Malafaia et al. 2003) e Princípios sobre suplementação mineral e a sanidade de ruminantes (Peixoto et al. 2005).

\section{EQUÍVOCOS SOBRE DEFICIÊNCIA E SUPLEMENTAÇÃO MINERAL EM BOVINOS}

1.) A essencialidade metabólica de um mineral sempre implicaria em sua suplementação obrigatória, via misturas minerais

Acredita-se que, independentemente da quantidade do(s) mineral(is) presente(s) nos alimentos volumosos, energéticos ou protéicos, vários ou o maior número deles ainda deveriam ser disponibilizados, sob forma das denominadas misturas minerais "completas" (MMCs), para que os animais tornem-se saudáveis e atinjam sua máxima produtividade. Tal prática, porém, além de não trazer qualquer benefício adicional, ainda representa um considerável acréscimo nos custos de produção e pode resultar na menor absorção, em função de antagonismos, daqueles minerais que realmente são necessários aos animais. Portanto, o fato de um determinado mineral ser metabolicamente essencial para os animais, não significa que ele deva ser necessariamente suplementado via misturas minerais. Para os bovinos, o cálcio $(\mathrm{Ca})$, potássio $(\mathrm{K})$, magnésio $(\mathrm{Mg})$, enxofre (S), ferro (Fe), cromo (Cr), níquel (Ni), dentre outros, são elementos essenciais, porém, sob condições naturais, dificilmente estarão deficientes nas dietas. Os estudos para induzir algumas dessas deficiências são realizados em condições altamente especializadas, o que equivale a dizer, praticamente artificiais (vide equívoco n.12).

2.) A suplementação mineral “dita completa" deveria ser sempre obrigatória em todas as regiões

Embora seja verdade que, no Brasil, tenhamos extensas áreas deficientes em um ou mais elementos minerais, em outras, pode não haver deficiência mineral alguma. Apenas para exemplificar, a região noroeste do Estado do Rio de Janeiro, sobretudo a cortada pelos rios Paraíba do Sul e Pomba, é deficitária apenas em sódio, enquanto que a microrregião de Itaguaí e Seropédica, somente em cobre; portanto, a suplementação com misturas "completas" representa um enorme desperdício de dinheiro dos pecuaristas destas regiões (Malafaia 2013). Mesmo a deficiência de sódio, praticamente difusa no país, não ocorre em locais onde as águas são salobras ou nas proximidades da orla marítima.

\section{3.) A suplementação mineral deveria ser sempre feita mesmo para animais submetidos a restrições nutricio- nais}

Pensa-se, de forma geral, que a suplementação mineral deveria ser praticada em qualquer situação e de forma ininterrupta ao longo do ano. No entanto, se levarmos em conta que uma das importantes funções dos minerais é a de serem cofatores exigidos para o perfeito funcionamento de várias enzimas, cujas funções em reações metabólicas só ocorrem quando existe uma adequada disponibilidade de carboidratos, lipídios e proteinas, percebe-se que animais que recebem dietas desbalanceadas nesses nutrientes não se beneficiam da suplementação mineral. Por exemplo, na época seca, quando sabidamente ocorrem grandes restrições qualitativas no valor nutritivo dos pastos (lignificação, menor relação folha:caules, redução do teor protéico e aumento nos teores dos carboidratos fibrosos indigeríveis), não há efeito benéfico da suplementação mineral sobre o desempenho dos animais, a menos que a dieta seja corrigida. Adicionalmente à restrição qualitativa, em muitos casos existe também a quantitativa, traduzida pela menor oferta de forragem para os animais. Se, durante a época seca, a oferta de forragem não for a principal limitação em uma fazenda, a deficiência de proteína e energia do pasto, seguramente, será o principal limitante ao desempenho dos animais. De tal maneira, pode-se ver que em várias regiões do Brasil, durante a época da seca, ocorre predominantemente a deficiência protéico-energética, que é a que deve ser corrigida, desde que de forma viável, prioritariamente à de fósforo ou a dos outros minerais (Malafaia et al. 2003).

\section{4.) Quanto maior o número de elementos incluídos na composição de uma mistura mineral, melhor ela seria}

Trata-se de uma crendice que pode até resultar em prejuízos à saúde ou à produção dos animais, uma vez que elementos não deficientes na dieta, e incluídos nas misturas minerais, podem antagonizar com outros realmente necessários. Infelizmente, muitos fazendeiros e técnicos "escolhem" suas misturas minerais baseados nessa crença. Em nossa experiência, na pesquisa ou no campo, fazendo experimentos ou viagens científicas, nunca encontramos mais de três minerais deficientes em um mesmo rebanho! 0 mais comum era, e é, observar-se a deficiência de Na associada a mais um mineral (P, Co, Cu ou Se). Assim sendo, a utilização das denominadas MMCs, constitui em enorme desperdício de dinheiro. Por outro lado, de forma pouco compreensível, as instruções normativas governamentais, a respeito da suplementação mineral, permitem a utilização de inúmeros 
minerais, com seus respectivos níveis de garantia, para que as MMCs possam ser comercializadas no Brasil.

\section{5.) Quanto maior a concentração do(s) elemento(s) mineral(is) em um suplemento, melhor ele seria}

Também não há base científica para sustentar essa crença. Se um grupo de animais carece de suplementação diária de $1,5 \mathrm{~g}$ de fósforo, não há razão para suplementar o dobro ou o triplo desta quantidade, uma vez que o excedente ingerido, e eliminado via fezes, é oneroso. 0 argumento segundo o qual, agindo dessa forma, se elevaria o teor de fósforo nas pastagens, não procede, pois essa prática seria uma forma muito cara e ineficiente de fertilizar os pastos com o fósforo, já que a distribuição dos excrementos não é uniforme, pois ocorre de forma muito concentrada nas áreas de "malhadouros" (próximas a cochos de sal, de água, ou locais mais sombreados) e em aproximadamente 5 a 10\% da área disponível para o pastejo (Haynes \& Williams 1993).

6.) Quanto maior o consumo diário de uma mistura mineral, melhor seria a qualidade dessa mistura e mais eficaz ela seria na correção dos estados carenciais dos rebanhos

A maior ou menor ingestão de uma mistura mineral reflete, antes de tudo, seu teor de cloreto de sódio. Uma vez adaptados, os bovinos adultos não ingerem mais que 30$50 \mathrm{~g}$ de $\mathrm{NaCl}$ por dia, mas se reduzirmos os teores desse ingrediente à metade ou a $25 \%$, como ocorre com algumas misturas minerais, os animais podem ingerir 120 até 200 g/dia dessas MMCs! Isto é péssimo para o proprietário que irá pagar, sem necessidade, pelas três a quatro vezes a mais que os bovinos irão ingerir das misturas minerais comerciais, já suficientemente caras. Em um levantamento feito a partir de cálculos baseados nas informações do teor de $\mathrm{Na}$ (em g/kg) em 15 misturas minerais, foram observados valores médios de $38,2 \%$ de $\mathrm{NaCl}$, com valor máximo de $65 \%$ e mínimo de 25\% (Malafaia \& Peixoto 2003). A utilização de misturas minerais com baixos teores de $\mathrm{NaCl}$, pode, dependendo do caso, produzir a deficiência de sódio no rebanho. Para se estimar o porcentual de $\mathrm{NaCl}$ em uma mistura mineral, deve-se dividir a quantidade de $\mathrm{Na}$, descrita no rótulo, por 0,40 . Por exemplo, uma MMC que contenha $140 \mathrm{gNa} /$ $\mathrm{kg}$ conterá cerca de $350 \mathrm{~g}$ de $\mathrm{NaCl} / \mathrm{kg}$ ou $35 \%$; então fica a pergunta: o que está contido nos outros $65 \%$ dessa mistura mineral? Não há como "fechar" essa fórmula para 100\% apenas com as fontes de $\mathrm{Mg}, \mathrm{K}, \mathrm{P}, \mathrm{S}$ e dos demais microminerais! Esse "fechamento" se dá por meio da inclusão de calcário que, além de baixar os custos de produção das MMCs, induz ao maior consumo diário da MMC! As indústrias também usam, como "enchimento", um grupo de silicatos denominados de caulim, que são inertes, insolúveis e indigestíveis. Portanto, os técnicos e pecuaristas cônscios não deveriam recomendar/utilizar misturas minerais com menos de 50\% de cloreto de sódio. Paradoxalmente, a Instrução Normativa N.12, publicada no D.O.U de 30-11-2004 determina que os suplementos minerais para pronto uso não devem ter mais de $60 \%$ de $\mathrm{NaCl}$ em sua composição. Dessa forma, a prática de inserir "enchimentos", apesar de tecnicamente não ter sentido, é amparada por lei.
7.) A formulação e a preparação de um suplemento mineral não deveria ser feita nas fazendas

Não se encontra justificativa para essa alegação, pois, ao nosso ver, qualquer profissional com bons conhecimentos de nutrição de ruminantes pode perfeitamente formular e preparar um suplemento mineral na fazenda. Alguns cuidados, porém, devem ser tomados na compra dos ingredientes, na mistura e na homogeneização dos elementos com o cloreto de sódio. Algumas vezes, porém, em função da logística, é necessário que a mistura mineral seja feita por alguma empresa idônea que misture os ingredientes formulados sempre com base no diagnóstico clínico-nutricional para um específico rebanho.

8.) Que a suplementação com cálcio é absolutamente necessária para bovinos, sobretudo os de elevada produção de leite

Em função de sua participação essencial como constituinte básico do esqueleto e de suas múltiplas funções no metabolismo dos animais e do homem, o cálcio é um dos minerais que tem recebido as maiores atenções, tanto na nutrição como na patologia animal. Como consequência, é um dos minerais frequentemente mais suplementados nas dietas dos bovinos. No Brasil, é prática comum a recomendação para adicionarem-se fontes de cálcio nos concentrados para os ruminantes (1 até 2,5\% de calcário calcítico) especialmente, para aqueles "mais produtivos" (Dayrell \& Campos 1995, Campos 2001a, 2001b). Outras recomendações sugerem o consumo deste elemento "forçado", isto é, presente nos suplementos minerais ("núcleos"), fornecidos entre 100 até $200 \mathrm{~g} /$ dia, especialmente para as vacas em lactação.

A alegação dos "nutricionistas" é que sem esta suplementação adicional, os animais ficariam deficientes e/ou diminuiriam a produção de leite. 0 curioso é que as equações descritas no manual do NRC para bovinos de leite (NRC, 2001, p.106-109) permitem apenas estimar as necessidades diárias de cálcio para os bovinos e em momento algum dão suporte ou indícios que validam as recomendações acima mencionadas. Por outro lado, há décadas, sempre baseados nos achados clínico-patológicos, propagamos que a adição de fontes de cálcio às dietas de vacas de leite, mesmo aquelas de alta produção, seria simples desperdício, uma vez que, sob condições naturais os bovinos sempre consomem a quantidade de cálcio necessária ao seu metabolismo e que as condições nas quais ocorreria a deficiência de cálcio configurariam erros na alimentação dos bovinos; isto é animais ingerindo mais de 60 ou $70 \%$ de grãos em sua dieta e por longos períodos. Nestes casos, antes de apresentarem a deficiência de cálcio, os animais padecem da acidose ruminal e todas as suas consequências danosas.

A deficiência de cálcio raramente ocorre nos bovinos criados exclusivamente a campo (Underwood \& Suttle, 1997, Tokarnia et al. 2010) e nas vacas de leite com produções de até $20 \mathrm{~kg} /$ dia (Canella \& Malafaia, 2013), pois o cálcio contido nos volumosos, mesmo os de menor qualidade, é suficiente para atender suas exigências. Nos animais de elevada produção de leite, que ingerem volumosos de melhor valor nutritivo (silagens de milho, fenos ou pré-secados) e uma considerável quantidade de concentrados, 
o cálcio contido nestas dietas pode não atender matematicamente à demanda dessas vacas e as pequenas diferenças entre o exigido e o ingerido não causam impactos negativos na saúde ou na produtividade dos animais. Para exemplificar, uma vaca com $550 \mathrm{~kg}$, produzindo $25 \mathrm{~kg} / \mathrm{dia}$ exige cerca de $86 \mathrm{~g} \mathrm{Ca} / \mathrm{dia}$. Se ela ingerir $2 \%$ de seu peso corporal em MS de capim tifton com $0,40 \%$ Ca e $1,45 \%$ de seu peso de um concentrado contendo $1 \mathrm{kgMS}$ de caroço de algodão $(0,23 \% \mathrm{Ca})+2,4 \mathrm{kgMS}$ de fubá $(0,03 \% \mathrm{Ca})+2,2$ kgMS de farelo de soja $(0,35 \% \mathrm{Ca})+2,4 \mathrm{kgMS}$ de casquinha de soja $(0,5 \% \mathrm{Ca})$ e beber $70 \mathrm{~L} /$ dia de água com $0,09 \mathrm{gCa} / \mathrm{L}$, a ingestão diária de cálcio chegará a $73 \mathrm{~g} /$ dia; portanto, um déficit de $13 \mathrm{~g} /$ dia. A pergunta que se deve fazer é: Qual é o impacto, em 1 ou 2 meses, que esse valor negativo causa na saúde ou na produtividade dessa vaca? Ao nosso ver, nenhum! A explicação é que esse animal é perfeitamente capaz de retirar cálcio de seu esqueleto para atender a esse déficit e que, com ao passar do tempo, a produção de leite declinará com o avançar da lactação e fará com que o pecuarista venha a reduzir o fornecimento dos concentrados e a vaca aumentará gradativamente a ingestão de pasto, sabidamente mais rico em cálcio, até que o balanço entre a exigência, a ingestão e a absorção se torne novamente positivo. Em geral essa crença se deve ao fato que os nutricionistas, em sua maioria, acreditam mais em números que em fatos biológicos.

Ainda vale ressaltar que se uma propriedade estiver em área deficiente em $\mathrm{P}$ e a suplementação deste mineral for feita com fosfato bicálcico, os animais receberão adicionalmente o cálcio presente nesse ingrediente.

\section{9.) Que a suplementação com ferro é necessária para ruminantes criados em pastagens ou para aqueles em recuperação após tratamentos contra hemoparasitoses}

De acordo com o conhecimento gerado sobre deficiências minerais, não se pode dar nenhum suporte científico a essas recomendações. Os alimentos forrageiros são ricos em ferro e a suplementação com esse mineral de nada adianta no restabelecimento dos animais, geralmente bezerros, tratados contra as principais hemoparasitoses. A exigência de ferro para bovinos de corte é de $50 \mathrm{mg} / \mathrm{kgMS}$ e os volumosos geralmente possuem 70 a $400 \mathrm{mgFe} / \mathrm{kgMS}$; logo um animal de $120 \mathrm{~kg}$ ingerindo 2,5\% de seu peso em MS, irá consumir $3 \mathrm{~kg} \mathrm{MS/dia} \mathrm{e} \mathrm{se} \mathrm{os} \mathrm{alimentos} \mathrm{utilizados}$ tiverem a menor concentração de Fe $(70 \mathrm{mg} / \mathrm{kg})$ ele estaria ingerindo $210 \mathrm{mgFe} /$ dia e precisaria de apenas 150 , o que não configura, portanto, um balanço negativo. Desde que corretamente tratado para uma determinada hemoparasitose, de nada adiantaria dar ferro adicional a este animal que já estaria ingerindo mais que sua exigência! Por outro lado, a inclusão de ferro em uma mistura mineral, além de ser desnecessária, pode reduzir a absorção do fósforo e causar a deficiência deste mineral, sabidamente importante para os bovinos. Surpreendentemente, por força das normativas governamentais, praticamente todas as MMCs brasileiras contém ferro nas suas fórmulas.

10.) Que as misturas minerais comerciais teriam um "equilíbrio" entre os distintos ingredientes que as com- põem ou não conteriam eventuais "enchimentos" desnecessários em suas fórmulas

A principal fonte de $\mathrm{P}$ nas misturas minerais é o fosfato bicálcico, que contém em média $18,5 \%$ de $\mathrm{P}$ e $23 \%$ de Ca e, portanto, uma relação Ca:P de 1,24:1. Com base nessa relação, é possível estimar o quanto de calcário uma determinada mistura mineral comercial (MMC) pode conter. Por exemplo, tomemos uma MMC cuja informação em seu rótulo diz que a mesma contém $160 \mathrm{~g}$ Ca e $88 \mathrm{~g}$ P por kg, logo uma relação Ca:P de 1,82:1. Se a mesma contivesse apenas fosfato bicálcico ela deveria ter $88 \times 1,24=109 \mathrm{~g} \mathrm{de} \mathrm{Ca} / \mathrm{kg}$; como possui 160 , estima-se que esta contém cerca de $51 \mathrm{~g}$ Ca advindas de outra fonte de $\mathrm{Ca}$, que normalmente é o calcário. Como o calcário contém 35\% Ca em sua composição, os excedentes $51 \mathrm{~g} \mathrm{Ca} / \mathrm{kg}$ equivalem a cerca de $145 \mathrm{~g}$ desse ingrediente por $\mathrm{kg}$ ou $14,5 \%$.

Assumindo que o calcário é extremamente barato para ser comprado (cerca de $\mathrm{R} \$ 50 / \mathrm{t}$ ) e que uma fábrica de MMC venda $100 \mathrm{t} /$ mês de uma fórmula encerrando 14 toneladas de calcário, ela gastaria $\mathrm{R} \$ 700$ com a compra do calcário e o venderia aos pecuaristas pelo preço de venda da referida MMC (R $\$ 2000 / t)$; ou seja, por 28000 reais, o que configura uma enorme margem de lucro. Algumas "fórmulas", por conterem exageradas quantidades de calcário (não é raro encontramos valores maiores que $20 \%$ ), são responsáveis pelo "notável" crescimento de algumas empresas. Essa grande lucratividade aliada à crença que o cálcio é deficitário aos bovinos (vide equívoco $n$. 8) explica por que muitos técnicos ou gerentes de fábricas de suplementos minerais advogam enfaticamente a necessidade de inserir cálcio nas misturas minerais comerciais no Brasil. Bastaria que os técnicos e pecuaristas não comprassem nenhuma fórmula que tivesse uma relação Ca:P maior que 1,40:1 para que se reduzisse a venda de calcário com o nome de suplemento mineral no Brasil.

\section{1.) Que a suplementação fosfórica deveria ser feita em todo rebanho nacional, pois os solos tropicais são pobres nesse elemento}

Do ponto da vista agronômico, isto é, para a produção viável de grãos, realmente a maioria dos solos brasileiros são limitantes em P. Mas, para a produção forrageira, isso não pode ser generalizado! Ao contrário, nossas pastagens, mesmo as dos solos de cerrado, podem atender mais que $80 \%$ das exigências de $\mathrm{P}$ dos bovinos de corte. Portanto, diferentemente do propagandeado, não são todos os solos brasileiros que podem produzir forragens realmente capazes de gerar deficiência de P. Nas áreas deficientes, sempre baseados no histórico, exame clínico e na experimentação (testes simples, pela verificação do desempenho geral do rebanho, frente à introdução do P), cada rebanho deveria ser suplementado de acordo com sua necessidade fosfórica. Por outro lado, há um verdadeiro "lobby" do P no Brasil, fomentado pelas empresas de suplementos minerais e, se não bastasse isso, é regra comum se ensinar nas universidades e propagar em centros de pesquisa que um "bom" suplemento mineral deve conter 6 a $8 \%$ de P. Isso não deveria ser a regra!

Outra "regra", que também causa muito desperdício de dinheiro e até poluição ambiental, é a suplementação 
fosfórica de bovinos independente de estarem ingerindo consideráveis quantidades de grãos e/ou seus subprodutos. Essa prática é bastante comum nos confinamentos e na bovinocultura leiteira. Por exemplo, um garrote de $350 \mathrm{~kg}$ ganhando $1,5 \mathrm{~kg} / \mathrm{dia}$, precisa de $24 \mathrm{~g}$ de $\mathrm{P} /$ dia. Se ele ingerir $1,5 \%$ de seu peso de matéria seca de um concentrado $(5250 \mathrm{~g} /$ dia) feito com $50 \%$ de fubá $(0,25 \%$ P), $15 \%$ de casquinha de soja $(0,16 \% \mathrm{P}), 15 \%$ farelo de soja $(0,6 \% \mathrm{P})$ e $20 \%$ de caroço de algodão $(0,7 \% \mathrm{P})$, ele irá consumir cerca de $20 \mathrm{~g} \mathrm{P} /$ dia. Se esse animal consumir $1,0 \%$ de seu peso em matéria seca de volumoso (3500g MS/dia) com 0,12\% de P, ele receberá toda sua necessidade de P via alimentos; não necessitando, portanto de ser fornecido $P$ adicional via suplementos minerais. Nesse exemplo, $0,12 \%$ de P no volumoso não é um valor elevado ou raro de ser observado nos volumosos suplementares de bovinos em confinamento!

\section{2.) Que a inclusão de enxofre nos suplementos mine- rais seria dieteticamente importante e ainda poderia minimizar a infestação por ectoparasitas}

A deficiência de enxofre foi sempre descrita em ruminantes criados em condições experimentais muito controladas, isto é, ingerindo dietas purificadas que continham níveis muito baixos desse mineral (Starks et al. 1953, Hale \& Garrigus 1953). Por outro lado, as exigências de enxofre para bovinos $(0,18 \%$ da MS) foram obtidas por Bouchard \& Conrad (1973) em um experimento onde as vacas recebiam $50 \%$ de silagem de milho e $50 \%$ da MS diária de um concentrado contendo $6 \%$ de ureia, $3 \%$ de gordura animal, 37 a $38,4 \%$ de amido de milho, $10 \%$ de "soybran flakes" e $40 \%$ de polpa de beterraba. Desse experimento, o NRC, em várias edições, "arredondou" o valor para 0,20\%! Ficam as perguntas: a) Os ingredientes utilizados naquele concentrado são usualmente fornecidos aos bovinos no Brasil? b) Se fossem, seriam ingeridos em aproximadamente $50 \%$ da MS exigida diariamente? c) Os bovinos, no Brasil, ingerem silagem de milho o ano todo? Como o espaço de inferência daquele experimento nos parece mínimo, é necessário que se duvide do valor $0,20 \%$ como referência da exigência dietética de S. Devemos nos prender ao fato de que a deficiência de enxofre ainda não foi descrita em animais criados em condições normais, isto é, aquela onde os animais são mantidos nas pastagens ou em sistemas semi-confinados ou até mesmo em confinamentos e ingerem alimentos proteicos (farelos de soja, de algodão ou de girassol, cevada, etc) que são considerados uma adequada fonte de enxofre para os microrganismos ruminais e também para o animal.

É bem sabido que animais que ingerem dietas com quantidades elevadas de ureia podem necessitar de serem suplementados com enxofre inorgânico para atender a relação $\mathrm{N}: \mathrm{S}$, que nos bovinos pode variar de 8 até 15:1 (Bouchard \& Conrad 1973). Nesses casos, o nutricionista deve atentar para os demais componentes da dieta e, sobretudo, da água que está sendo ofertada, pois é comum águas com teores significativos de $\mathrm{S}$ no Brasil. Portanto, sempre é necessário refletir se é mesmo necessário adicionar S em dietas para os ruminantes. Malafaia (2010) acompanhou, por três anos, cinco propriedades que utilizaram cana-de-açúcar (20-25 $\mathrm{kg} / \mathrm{animal} / \mathrm{dia}$ ) adicionada com $0,8 \%$ de ureia, sem sulfato de amônio, durante a época da seca e não percebeu qualquer "problema" relacionado com a "falta" do enxofre.

Outro ponto, ainda sob investigação, é a possível relação entre a polioencefalomalácia e o consumo excessivo de enxofre, sob forma de sulfatos, por ruminantes (Goud 2000, Delfiol et al. 2013). Também é necessário lembrar que o excesso de $\mathrm{S}$ pode causar a deficiência secundária de cobre. Portanto, ao nosso ver, os riscos da suplementação com enxofre são maiores que os supostos benefícios que a sua falta poderia resultar.

Em relação ao uso da flor de enxofre (enxofre elementar), é pertinente lembrar que trata-se de um ingrediente muito insolúvel e inerte, ou seja, pouquíssimo assimilável durante sua permanência no tubo digestivo. Seu uso não serve para prover enxofre, pois os microrganismos ruminais exigem sulfatos $\left(\mathrm{SO}_{4}{ }^{-}\right)$e não enxofre elementar para a síntese da proteína microbiana. Por outro lado, a alegação que a flor de enxofre minimiza a infestação por carrapatos não tem a menor base científica e, a menos que resultados de pesquisas sejam publicados em periódicos de elevado rigor e relevância veterinária, essa ideia deve ser abolida.

\section{3.) Suplemento mineral "bom" é aquele que não em- pedra}

Muitas vezes se escuta pecuaristas e vaqueiros dizerem que se o suplemento mineral "empedra", ele não é bom. Trata-se de mais uma observação equivocada, pois na verdade se o suplemento mineral contiver apenas cloreto de sódio e outros ingredientes minerais de alta biodisponibilidade, ele será higroscópico e irá "empedrar". Como isso implica em mais trabalho para as pessoas que lidam com o rebanho, já que elas terão que ir aos cochos de sal mineral para "destorroarem" manualmente o suplemento, elas passam a "preferir" os produtos feitos com mais calcário e com ingredientes mais insolúveis que são, entretanto, menos biodisponíveis, mas que ficam "soltinhos" nos cochos. Portanto, contrariamente ao propagandeado, sal mineral bom empedra! Porém, é necessário lembrar que pode ocorrer redução no consumo diário de uma dada mistura mineral devido ao seu "empedramento" e que cochos com cobertura adequada, aliada à constante fiscalização dos cochos, evita tal problema.

\section{CONSIDERAÇÕES FINAIS}

Dois aspectos podem ser considerados como fundamentais no que diz respeito à suplementação mineral dos bovinos. 0 mais importante é estabelecer, com base no histórico e exame clínico, se há ou não deficiência(s) mineral(is) em determinada fazenda ou região. Uma vez comprovada a(s) deficiência(s), deve-se suplementar somente aquele(s) mineral(is) cuja(s) deficiência(s) foi(ram) diagnosticada(s). De forma geral, o suplemento mineral pode ser preparado na própria fazenda, em cooperativas ou por empresas idôneas. A assistência técnica contínua, feita por profissional capacitado, é a forma correta de se avaliar, propor alterações e implantar um esquema de suplementação mineral em uma fazenda.

Em segundo lugar, considerando-se que as crenças e equívocos cometidos em relação à suplementação mineral 
realizada rotineiramente no Brasil, confundem e causam prejuízos econômicos aos pecuaristas, torna-se necessário modificar essa situação, o quanto antes. A forma mais eficaz, passa pela correta capacitação (leia-se acesso à informações científicas fidedignas, não relacionadas à simples propaganda comercial) de professores e profissionais nas áreas de zootecnia e veterinária.

Agradecimentos.- Pedro Malafaia expressa seus agradecimentos aos Professores Carlos Augusto B. Carvalho (UFRRJ), Douglas S. Henrique (UFPR), Luciano S. Cabral (UFMT) e Ricardo A.M. Vieira (UENF) pelas valiosas sugestões e correções no manuscrito.

\section{REFERÊNCIAS}

Bouchard R. \& Conrad H.R. 1973. Sulfur requirement of dairy cattle. 1. Sulfur balance and dietary supplementation. J. Dairy Sci. 56(10):12761282.

Campos O.F. 2001a. Opções de concentrados para bezerros até os 360 dias de idade. Instrução Técnica para o Produtor de Leite no.39, Embrapa Gado de Leite, Juiz de Fora, MG.

Campos O.F. 2001b. Opções de concentrados para vacas em lactação. Instrução Técnica para o Produtor de Leite. no.40, Embrapa Gado de Leite, Juiz de Fora, MG.

Canella C.F.C. \& Malafaia P. 2013. Dados não publicados (Universidade Federal Rural do Rio de Janeiro, Seropédica, RJ).

Dayrell M.S. \& Campos O.F. 1995. Opções de concentrados para vacas em lactação. Orientações Técnicas para o Produtor de Leite no.16, Embrapa-CBPGL, Coronel Pacheco, MG.

Delfiol D.J.Z., Cagnini D.Q., Cunha P.H.J., Crosignani N., Wouters A.T.B., Wolters F., Driemeier D. \& Borges A.S. 2013. Aspectos clínicos e laboratoriais em ovinos submetidos a dietas com níveis elevados de enxofre com objetivo de indução de polioencefalomalácia. Pesq. Vet. Bras. 33(4):435-442.

Gould D.H. 2000. Update on sulphur-related polioencephalomalacia. Vet. Clin. North Am., Food Anim. Pract. 16(3):481-496.
Hale W.H. \& Garrigus U.S. 1953. Synthesis of cystine in wool from elemental sulfur and sulfate sulfur. J. Anim. Sci. 12(3):492-496.

Haynes R.J. \& Williams P.H. 1993. Nutrient cycling and soil fertility in the grazed pasture ecosystem. Adv. Agron. 49:119-199.

Malafaia P. 2010. Dados não publicados (Universidade Federal Rural do Rio de Janeiro, Seropédica, RJ).

Malafaia P. 2013. Dados não publicados (Universidade Federal Rural do Rio de Janeiro, Seropédica, RJ).

Malafaia P. \& Peixoto P.V. 2003. Dados não publicados (Universidade Federal Rural do Rio de Janeiro, Seropédica, RJ).

Malafaia P., Cabral L.S., Vieira R.A.M., Magnoli Costa R. \& Carvalho C.A.B. 2003. Suplementação protéico-energética para bovinos criados em pastagens: Aspectos teóricos e principais resultados publicados no Brasil. Livestock Research for Rural Development 15(12). <http://www.lrrd. org/lrrd15/12/mala1512> Acessado em 24 out. 2013.

Malafaia P., Peixoto P.V., Gonçalves J.C.S., Moreira A.L., Costa D.P.B. \& Correa W.S. 2004. Ganho de peso e custos em bovinos de corte submetidos a dois tipos de suplementos minerais. Pesq. Vet. Bras. 24(3):160-164.

NRC 2001. Nutrient Requirements of Dairy Cattle. $7^{\text {th }}$ ed. National Research Council, National Academy Press, Washington, DC. 381p.

Peixoto P.V., Malafaia P., Miranda L.V., Canella C.F.C., Canella Filho C.F.C. \& Vilas Boas F.V. 2003. Eficiência reprodutiva de matrizes bovinas de corte submetidas a três diferentes tipos de suplementação mineral. Pesq. Vet. Bras. 23(3):125-130.

Peixoto P.V., Malafaia P., Barbosa J.D. \& Tokarnia C.H. 2005. Princípios de suplementação mineral em ruminantes. Pesq. Vet. Bras. 25(3):195200.

Starks P.B., Hale W.H., Garrigus U.S. \& Forbes R.M. 1953. The utilization of feed nitrogen by lambs as affected by elemental sulfur. J. Anim. Sci. 12(3):480-491.

Tokarnia C.H., Peixoto P.V., Barbosa J.D., Brito M.F. \& Döbereiner J. 2010. Deficiências Minerais em Animais de Produção. Helianthus, Rio de Janeiro. 191p.

Underwood E.J. \& Suttle N.F. 1997. The Mineral Nutrition of Livestock. CABI Publishing, London. 609p. 